\title{
Nicole Bhattacharya, Joë Bousquet. Une expérience spirituelle
}

\section{Emanuele Kanceff}

\section{Q OpenEdition}

10 Journals

\section{Édition électronique}

URL : https://journals.openedition.org/studifrancesi/41152

DOI : 10.4000/studifrancesi.41152

ISSN : 2421-5856

\section{Éditeur}

Rosenberg \& Sellier

\section{Édition imprimée}

Date de publication : 1 juillet 2004

Pagination : 220

ISSN : 0039-2944

\section{Référence électronique}

Emanuele Kanceff, «Nicole Bhattacharya, Joë Bousquet. Une expérience spirituelle », Studi Francesi [En ligne], 142 (XLVIII | I) | 2004, mis en ligne le 30 novembre 2015, consulté le 09 septembre 2021. URL: http://journals.openedition.org/studifrancesi/41152; DOI : https://doi.org/10.4000/studifrancesi. 41152

Ce document a été généré automatiquement le 9 septembre 2021.

\section{(c)}

Studi Francesi è distribuita con Licenza Creative Commons Attribuzione - Non commerciale - Non opere derivate 4.0 Internazionale. 


\title{
Nicole Bhattacharya, Joë Bousquet. Une expérience spirituelle
}

\author{
Emanuele Kanceff
}

\section{RÉFÉRENCE}

NICOLE BHATTACHARYA, Joë Bousquet. Une expérience spirituelle, Genève, Droz, 1998, pp. 484

(«Histoire des idées et critique littéraire», 364).

1 Questo dotto e serrato volume è il condensato di una tesi di dottorato di stato, e ne mostra ancora i segni nella serietà e puntualità didascalica, nella finitezza degli apparati, nella costruzione rigorosa. L'autrice interpreta l'esperienza spirituale di Bousquet come l'elemento primo della sua poesia e la vede come una insorgenza dell'infinito nella finitudine. Per penetrare nel cuore della sua espressione, occorre rifarsi al cammino che, durante tutta la vita, ha permesso al poeta di esprimere, in modi diversi, una intuizione centrale indicibile.

2 Per portare a termine il suo tragitto di ricerca, l'autrice ha dovuto scontrarsi in molteplici difficoltà: «Notre principe a été de serrer les textes de très près. Dans ce travail nous nous sommes heurtée à deux difficultés. Un corpus mal délimité, où règne le désordre. Non seulement il existe encore nombre d'inédits, et bien des articles de Bousquet sont dispersés dans des revues introuvables, mais les textes disponibles offrent un maquis, où le même fragment peut figurer jusqu'à quatre ou cinq fois à travers les œuvres publiées par Bousquet lui-même, les œuvres posthumes, la correspondance et les divers «Cahiers». [...] En outre, Bousquet est un écrivain hermétique: la plupart de ses phrases prêtent insidieusement à contresens, et les plus simples d'apparence sont souvent celles dont le sens est le plus dérobé. C'est pourquoi nous avons cru devoir accompagner la majeure partie des citations de quelques mots d'interprétation».

3 Ma certamente il risultato di tanta fatica e di così amorose attenzioni è eccellente: dalla ricerca di un itinerario in relazione con il suo paesaggio interiore, attraverso l'esame 
puntuale delle prospettive scoperte, il cammino fervente verso l'Essere, Nicole Bhattacharya ci svela dimensioni che sono in grado di modificare e interiorizzare notevolmente la lettura dell'opera, che volentieri vediamo «suspendue entre deux abîmes - l'Un absolu, Point suprême inconnaissable, et la Création, naufrage de l'Un dans le Multiple». In sostanza, «l'Unité instable de l'Être est à reconquérir éternellement». 